\title{
Liver enzymes as surrogate markers of hepatitis $C$ histopathology - Avoiding the liver biopsy needle?
}

\section{Stephen GM Wong BSc(Med) MD FRCPC, Eric M Yoshida MD MHSc FRCPC}

\section{ARTICLE}

Assy N, Minuk GY. Serum aspartate but not alanine aminotransferase levels help to predict the histological features of chronic hepatitis $\mathrm{C}$ viral infections in adults. The American Journal of Gastroenterology 2000;95:1545-50.

\section{ARTICLE SUMMARY}

A retrospective cohort study of 79 patients with chronic hepatitis $\mathrm{C}$ was performed to assess the predictive nature of various variables (age, sex, route of transmission, extent of steatosis, alcohol consumption and serum aminotransferase values), with the underlying hepatic histopathology. The newly modified Knodell histological activity index by Desmet et al (1), which separately scores the inflammation from the fibrosis on the liver biopsy, was used. Using stepwise multivariate logistic regression, it was discovered that serum aspartate aminotransferase (AST) values had a predictive relationship with overall histological activity $(\mathrm{r}=0.62)$, portal inflammation $(\mathrm{r}=0.58)$, piecemeal necrosis $(\mathrm{r}=0.61)$ and extent of hepatic fibrosis $(\mathrm{r}=0.64)$. Serum AST values correctly predicted the inflammatory grade in 63 of $79(80 \%)$ patients, and the fibrosis stage in 50 of 79
(63\%) patients - higher than the predictive values of ALT. Serum alanine aminotransferase (ALT) values did not correlate with the degree of histological inflammation $(\mathrm{r}=0.39)$ but did correlate mildly with the extent of hepatic fibrosis $(\mathrm{r}=0.51)$. There were no significant correlations of the other variables with histological inflammation or fibrosis.

\section{COMMENTARY}

Although Menghini (2) described the 'one second' liver biopsy over 40 years ago, the liver biopsy has maintained its position in modern medicine as the cornerstone to understanding liver diseases. In patients with hepatitis $C$, the liver biopsy can provide important information regarding the extent and severity of the hepatitis, the likelihood of progression to cirrhosis and the potential response to medical therapy $(3,4)$. However, the acquisition of this valuable information occurs at the expense of performing an invasive procedure with inherent risks and complications, including death (5-7). Thus, the search for noninvasive, surrogate markers that can predict the underlying histopathology is enticing.

Many surrogate markers have been investigated, of which the aminotransferases are the best studied. Along with AST, the AST to ALT ratio has been suggested as a predictor of histopathology by many studies; however, other 
studies have produced conflicting results (8-11). The present study has shed further light in this area, because AST, and not ALT, levels seem to correlate positively with hepatic inflammation and fibrosis using Desmet's modified histological activity index scale. Nevertheless, despite the liver biopsy technique remaining essentially unchanged over the years, the hepatitis histopathology classifications

\section{REFERENCES}

1. Desmet VJ, Gerber M, Hoofnagle JH, et al. Classification of chronic hepatitis: Diagnosis, grading, and staging. Hepatology 1994;19:1513-20.

2. Menghini G. One-second needle biopsy of the liver. Gastroenterology 1958;35:190-9.

3. Yano M, Kumada H, Kage M, et al. The long-term pathological evolution of chronic hepatitis C. Hepatology 1996;23:1334-40.

4. Davis GL, Lau JY. Factors predictive of a beneficial response to therapy of hepatitis C. Hepatology 1997;26(3 Suppl 1):122S-7S.

5. Minuk GY, Sutherland LR, Wiseman DA, MacDonald FR, Ding DL. Prospective study of the incidence of ultrasound-detected intrahepatic and subcapsular hematomas in patients randomized to 6 or 24 hours of bed rest after percutaneous liver biopsy. Gastroenterology 1987;92:290-3.

6. Bravo AA, Sheth SG, Chopra S. Liver biopsy. N Engl J Med 2001;344:495-500. have undergone many revisions. The current grading and staging classification system described by Batts and Ludwig (12) in 1995 has now become the standard. Surrogate marker studies with this new classification system are still pending. Thus, the pursuit of a noninvasive and predictive marker for liver histology will continue as we try to avoid the liver biopsy needle for our patients.

7. Poynard T, Ratziu V, Bedossa P. Appropriateness of liver biopsy. Can J Gastroenterol 2000;14:543-8.

8. Anderson FH, Zeng L, Rock NR, Yoshida EM. An assessment of the clinical utility of serum ALT and AST in chronic hepatitis C. Hepatol Res 2000;18:63-71.

9. Reedy DW, Loo AT, Levine RA. AST/ALT ratio $>$ or $=1$ is not diagnostic of cirrhosis in patients with chronic hepatitis C. Dig Dis Sci 1998;43:2156-9.

10. Imperiale TF, Said AT, Cummings OW, Born LJ. Need for validation of clinical decision aids: use of the AST/ALT ratio in predicting cirrhosis in chronic hepatitis C. Am J Gastroenterol 2000;95:2328-32.

11. Giannini E, Testa R. Is aspartate aminotransferase enough? Am J Gastroenterol 2000;95:3687-8.

12. Batts KP, Ludwig J. Chronic hepatitis. An update on terminology and reporting. Am J Surg Pathol 1995;19:1409-17. 


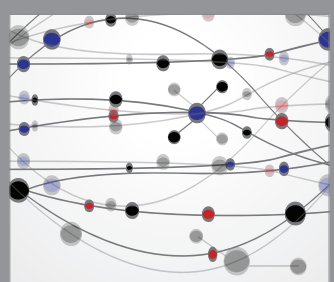

The Scientific World Journal
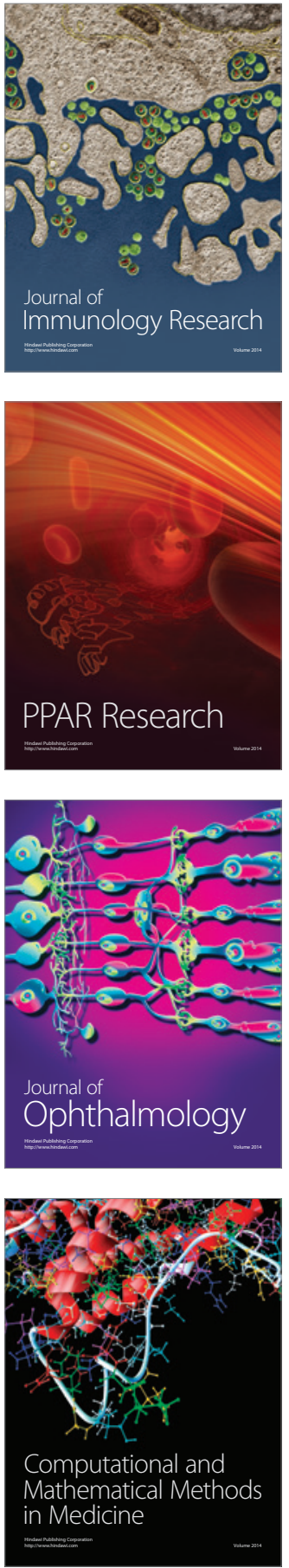

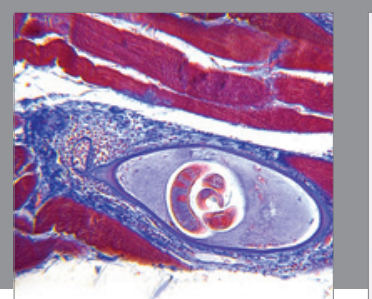

Gastroenterology Research and Practice

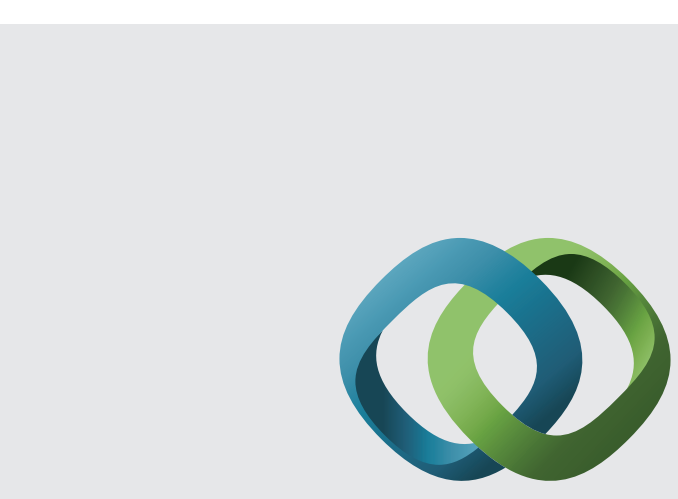

\section{Hindawi}

Submit your manuscripts at

http://www.hindawi.com
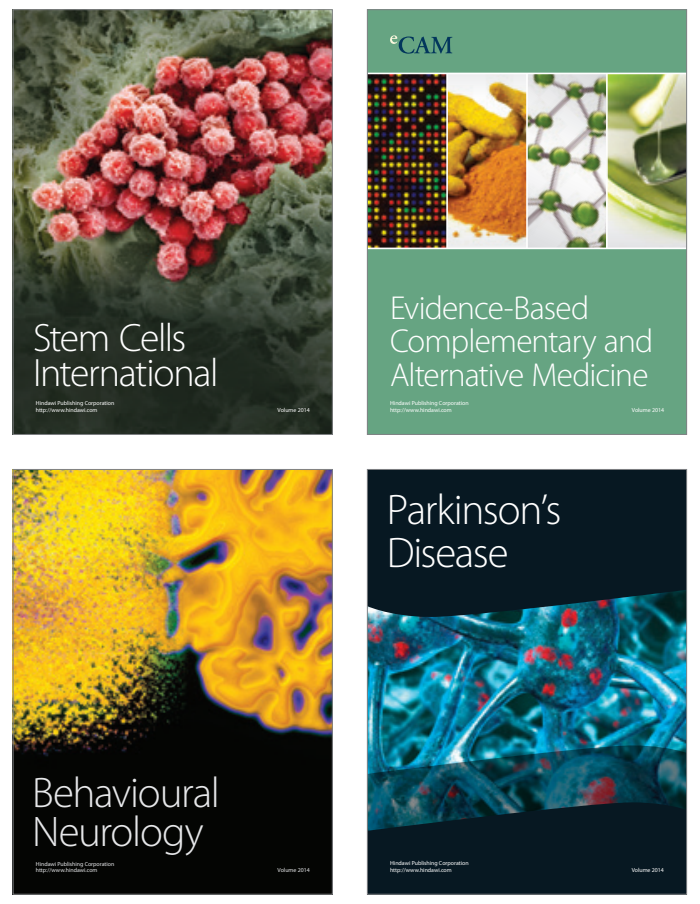
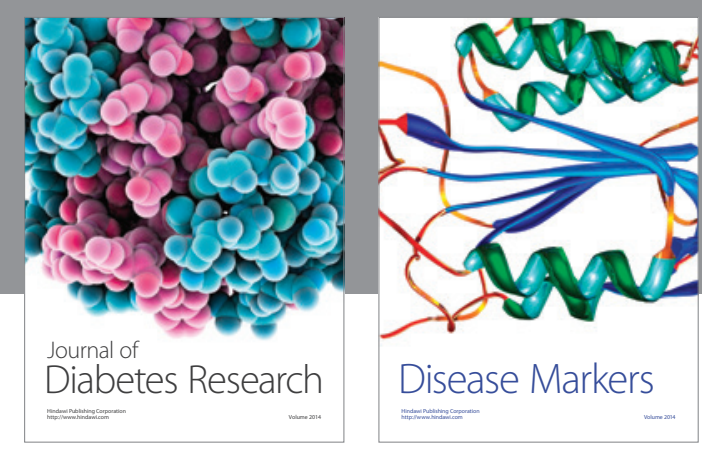

Disease Markers
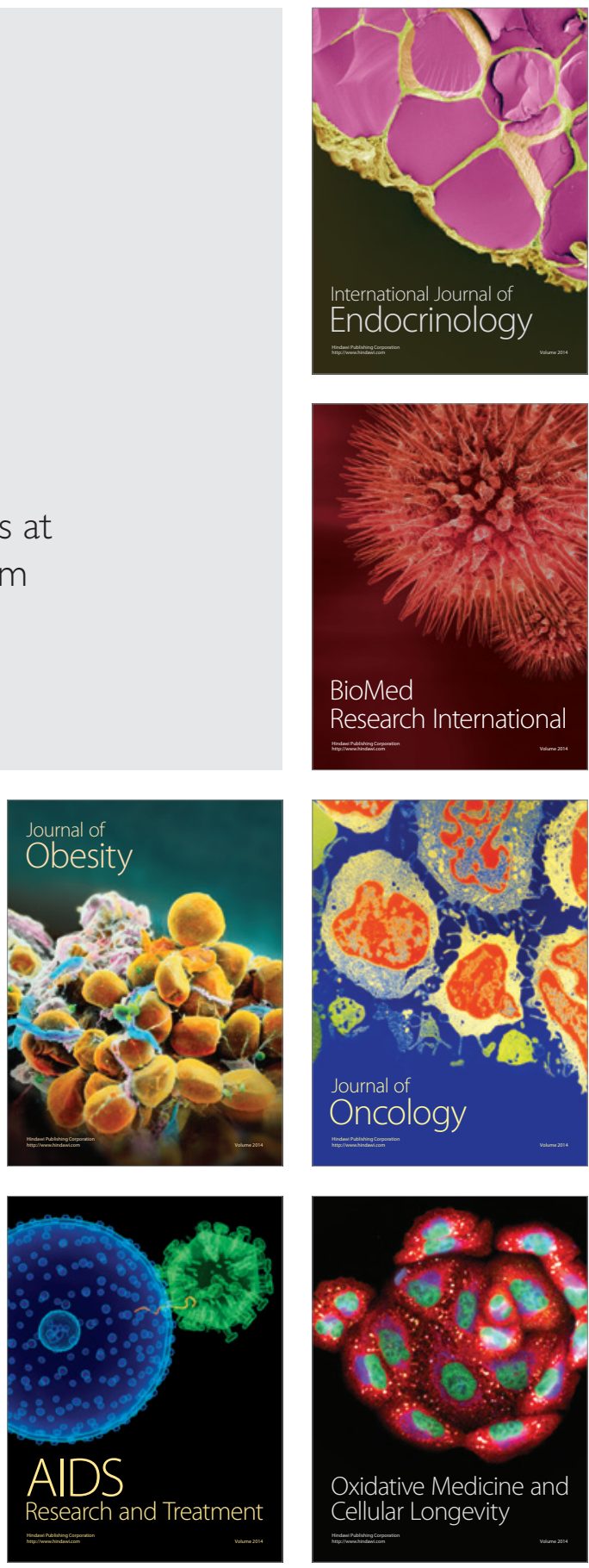